\title{
COMPUTATIONAL METHODS OF HEAT AFFECTED ZONE DETERMINATION DURING ARC WELD SURFACING
}

\author{
${ }^{1}$ Mateusz MATUSZEWSKI, ${ }^{2}$ Radoslav KOŇÁR, ${ }^{3}$ Daniel HARMANIAK, ${ }^{4}$ Andrzej ZABORSKI \\ 1Czestochowa University of Technology, Czestochowa, Poland, EU, matuszewski@itm.pcz.pl \\ 2University of Zilina, Zilina, Slovak Republic,EU, radoslav.konar@fstroj.uniza.sk \\ 3University of Zilina, Zilina, Slovak Republic, EU, daniel.harmaniak@fstroj.uniza.sk \\ ${ }^{4}$ Czestochowa University of Technology, Czestochowa, Poland, EU, zaborski@itm.pcz.pl
}

https://doi.org/10.37904/metal.2020.3531

\begin{abstract}
In the paper, the methods for determining heat affected zones during arc weld surfacing is presented. For this purpose, numerical simulations of the temperature field were performed using the Ansys and Sysweld programs based on the finite element method. The Goldak heat source model was used in the computations. Based on the maximum temperature values, the characteristic heat affected zones (remelting zone, fusion line, austenitization zone) have been determined. The results of calculations were compared with the boundaries of individual zones determined by the analytical method using a double volumetric Gaussianparabolic heat source model and obtained experimentally. Finally, the possibility of mapping the fusion line was assessed using particular heat source methods, programs and models.
\end{abstract}

Keywords: Modelling, welding heat source, heat affected zone, submerged arc welding, fusion line, finite element method

\section{INTRODUCTION}

Since mid-last century, solutions have been sought to describe the temperature field in welding processes, taking into account the temperature-dependent properties of the material. For this purpose, both numerical methods are used (mainly the FEM - Finite Element Method) [1,2], as well as analytical solutions [3 - 5].

Experimental verification of the temperature field model can be performed by direct methods (measurement using thermocouples [6], thermal imaging camera [7] or indirectly by cross-sectional metallographic examination determination of heat affected zones and structural analysis of the material) $[8,9]$.

One of the problems is the mapping of irregular shapes of the fusion lines often occurring during weld surfacing $[10,11]$, which is related to the selection of the heat source model $[12,13]$. Among many models of heat sources, Gaussian flat [14], volumetric Goldak's [15], elliptic paraboloid [16] and models with an axis inclined to the bead $[17,18]$ can be mentioned. This paper analyzes various methods of calculating the temperature field during the SAW (Submerged Arc Welding) surfacing and determining heat affected zones. The considerations were presented by comparing temperature distributions and fusion lines obtained by numerical methods (using the professional programs Ansys and Sysweld) and analytical [19], as well as the results of experimental studies [20].

\section{SUBJECT OF STUDY}

A steel element surfaced with the SAW method was selected for the numerical analysis of the temperature field, the experimental research of which was described in [20]. In the weld cladding tests, a $30 \mathrm{~mm}$ thick 200 
$x 200 \mathrm{~mm}$ steel plate S355J2H3 was given. The surfacing was made with welding velocity $0.5 \mathrm{~m} / \mathrm{min}$, voltage $30 \mathrm{~V}$ and current $400 \mathrm{~A}$. The macroscopic structure of the surfacing weld deposit is shown in Figure 1.

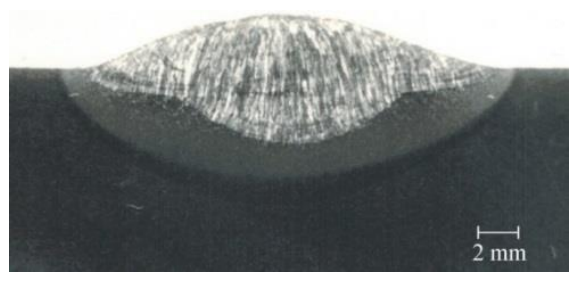

Figure 1 Macrostructure of deposit weld [20]

\section{DETERMINATION OF HEAT AFFECTED ZONES BY NUMERICAL METHODS}

For this purpose, the professional programs Ansys and Sysweld were used. Both computational systems are based on the finite element method. Ansys is a universal engineering program. The Sysweld is dedicated to modeling of welding and heat treatment processes, and the correctness of the results of numerical simulations performed using this program are confirmed by experimental research and industrial practice $[21,22]$. The calculations assumed technological parameters, the material and geometry of the surfaced object used in the experiment.

In both calculation examples, the double-ellipsoidal Goldak heat source model was adopted (Figure 2). The Goldak's volumetric heat source model consists of two parts (in relation to the welding direction): front and rear. Front volume of heat source is described by equation:

$q_{f}(x, y, z)=\frac{6 \sqrt{3} f_{f} Q}{a b c \pi^{1.5}} \exp \left(\frac{-3 x^{2}}{a^{2}}\right) \exp \left(\frac{-3 y^{2}}{b^{2}}\right) \exp \left(\frac{-3 z^{2}}{\left(c_{f}\right)^{2}}\right)$

and a rear part:

$q_{r}(x, y, z)=\frac{6 \sqrt{3} f_{r} Q}{a b c \pi^{1.5}} \exp \left(\frac{-3 x^{2}}{a^{2}}\right) \exp \left(\frac{-3 y^{2}}{b^{2}}\right) \exp \left(\frac{-3 z^{2}}{\left(c_{r}\right)^{2}}\right)$

where: $a, b, c_{f}, c_{r}$ are the geometric parameters of the ellipsoidal heat source, $f_{f}$ and $f_{r}$ proportionality coefficients corresponding to heat in the front and rear parts of the heat source respectively, where $f_{f}+f_{r}=2, \xi$ is distance of current source position to point $(x, y, z)$.

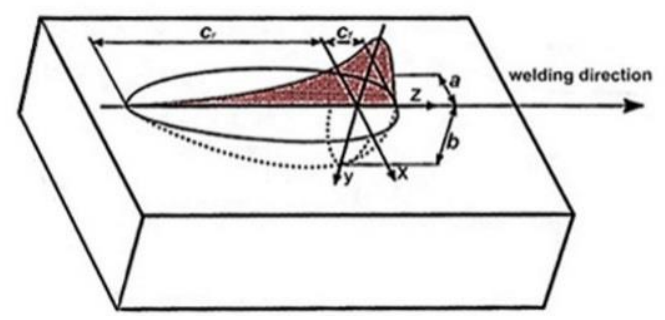

Figure 2 Characteristic dimensions of Goldak's model of heat source

Temperature field simulations were performed under the following boundary conditions:

$T_{s}=f(x, y, z, t)$

$q_{s}=-k \frac{d T(0, t)}{d x}$

$q_{\text {conv }}=h\left(T_{\text {free }}-T_{w}\right)$ 
$q_{\text {rad }}=\varepsilon \sigma\left(T_{\infty}^{4}-T_{w}^{4}\right)$

where: $T_{s}$ - local solid temperature, $q_{s}$ - heat flux, $k$ - thermal conductivity, $h$-fluid-side local heat transfer coefficient, $\varepsilon$ - emissivity of the external wall surface, $\sigma$-Stefan-Boltzmann constant, $q_{\text {rad }}$ - radiative heat flux to the wall from within the domain, $q_{\text {conv }}$ - convective heat loss from the wall, $T_{\text {free }}$ - local fluid temperature, $T_{w}$ - surface temperature on the wall, $T_{\infty}$ - temperature of the radiation source or sink on the exterior of the domain, $t$ - time.

\subsection{Computation of the temperature field and determination of HAZ using the Ansys program}

The following dimensions of the Goldak source were used in the temperature field calculations: $a=0,0125 \mathrm{~m}$, $b=0,0095 \mathrm{~m}, c_{f}=0,004 \mathrm{~m}$ i $c_{r}=0,009 \mathrm{~m}$. The geometric body model is divided into 279295 elements and contains 205788 nodes, the distribution of which in cross section is shown in Figure 3.

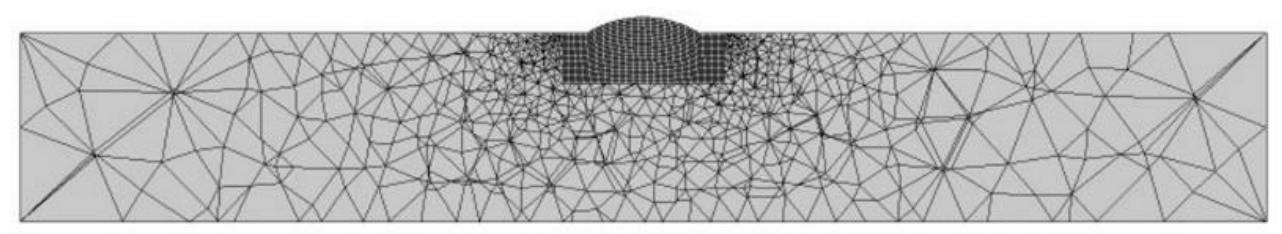

Figure 3 Division into finite elements - cross section of the surfacing element

Comparison of the distribution of maximum temperature values during surfacing in relation to the fusion zone and the heat affected zone visible on the metallographic specimen is shown in Figure 4a. The calculated penetration depth measured in the middle of the deposit (red line in Figure $\mathbf{4 b}$ ), as well as the depth of the heat affected zone (yellow line) are consistent with the results of the experiment. However, the width of the fusion zone measured on the surface of the welded element $(13.8 \mathrm{~mm})$ is significantly different from that measured on the metallographic specimen. Similarly, the shape of the heat-affected zone, fusion line and boundary of austenitic transformation (heat-affected zones) is clearly different from that obtained in the experiment.

a)

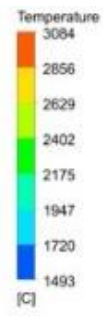

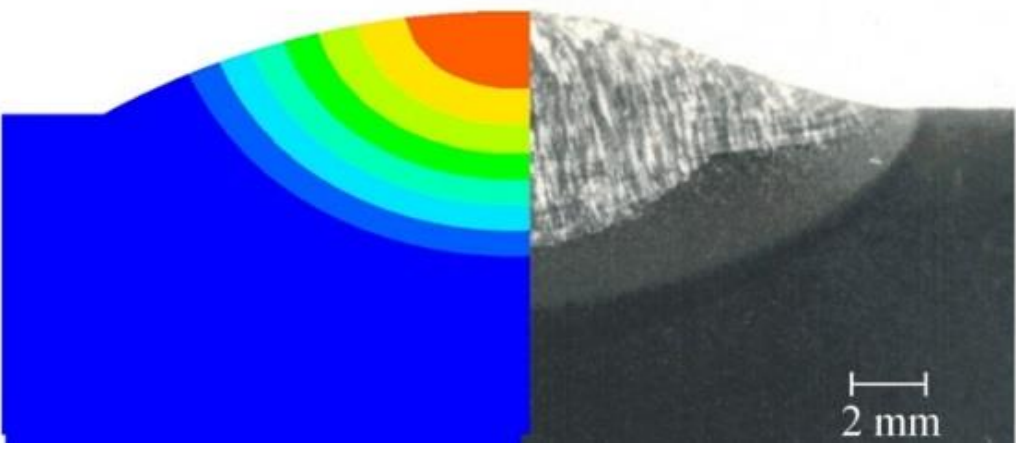

b)

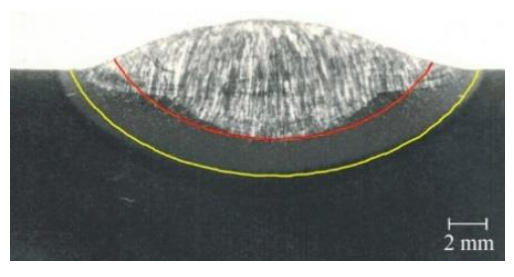

Figure 4 Maximum temperature distribution, Heat Affected Zones and their limits in comparison with the result of the experiment

\subsection{Computation of the temperature field and determination of HAZ using the Sysweld program}

The following dimensions of the Goldak heat source were used in the temperature field calculations: $a=0.01$ $\mathrm{m}, b=0.003 \mathrm{~m}, c_{f}=0.0033 \mathrm{~m}$ i $c_{f}=0.00667 \mathrm{~m}$. Half of the analyzed surfacing element was adopted in the considerations due to the symmetrical distribution of the heat load and the theoretical temperature field. The 
geometric body model is divided into 33542 elements and contains 31656 nodes, the distribution of which in cross-section is shown in Figure $\mathbf{5 a}$.

The molten weld area obtained using the Goldak heat source model has a regular elliptical shape, which is often not like a real fusion zone. The Sysweld program allows the correction of the thermal load of finite mesh elements. The 3D LOAD function is used to define the energy distribution in the model of the weld. The welding input energy is distributed to the model through elements depending on welding penetration. The modified heat load of the weld elements adopted in the calculations is presented in Figure $\mathbf{5 b}$.

a)

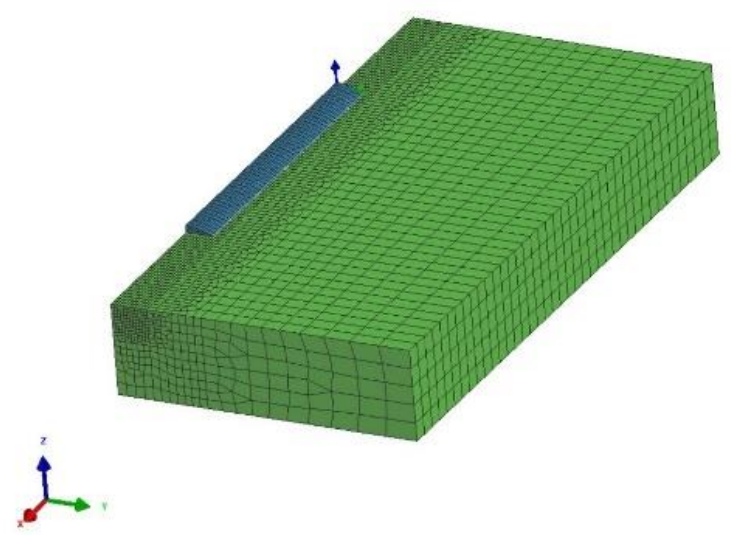

b)

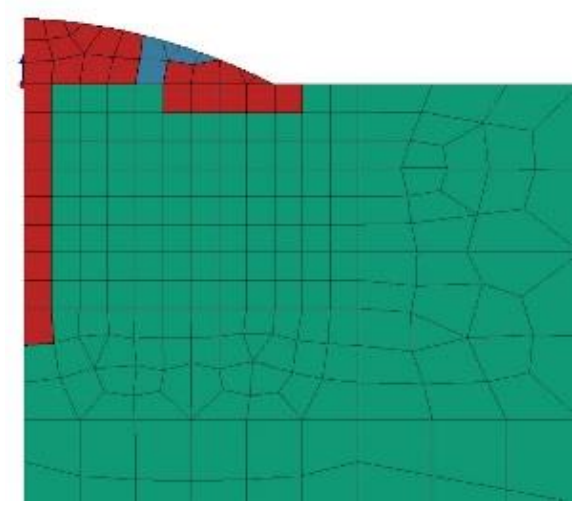

Figure 5 Model adopted for calculations: a) division into finite elements; b) thermal load of elements

Based on the maximum temperature, heat affected zones have been determined as shown in Figure 6 . The fusion zone is marked with purple, while the full zone (between $876^{\circ} \mathrm{C}$ and $1439^{\circ} \mathrm{C}$ ) and incomplete (between $727^{\circ} \mathrm{C}$ and $876{ }^{\circ} \mathrm{C}$ ) austenitic transformation are marked with yellow and light blue (blue) respectively. Native material that has not undergone structural changes is marked in dark blue. Finite elements in the shape of a square shown in the figure have a side length of $1 \mathrm{~mm}$. The obtained shapes and dimensions of heat affected zones in numerical simulations are consistent with the results of experimental research.

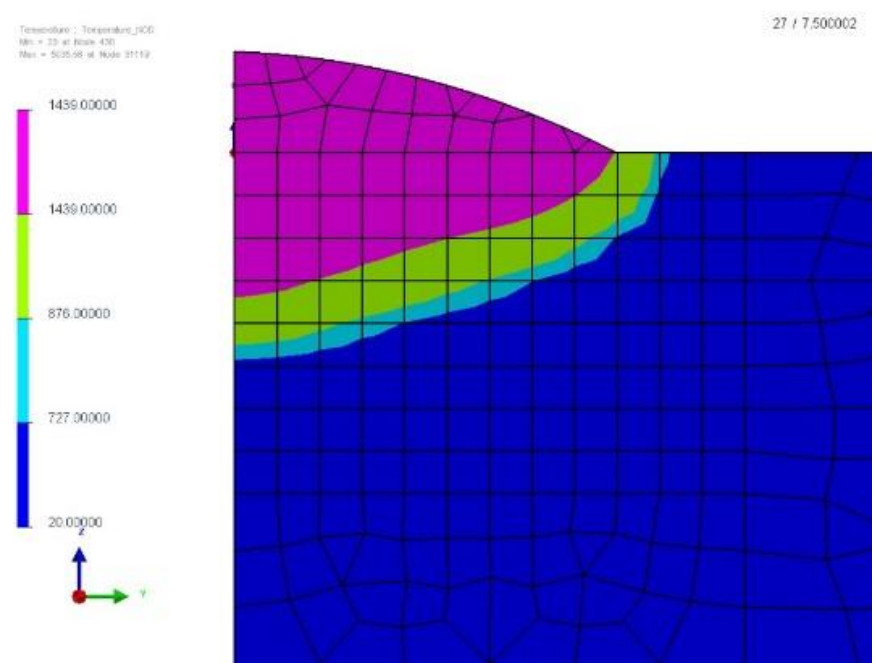

Figure 6 Heat affected zones determined using the Sysweld program

\section{ANALYTICAL SOLUTION}

In paper [19] a double volumetric Gaussian-parabolic heat source model has been proposed that allows obtain an irregular shape of the fusion line. The solution was based on the assumption that part of the heat generated 
in the electric arc is consumed by melting the electrode material and transferred to the surfacing droplet, and the remaining amount of heat directly affects the surfaced material.

In the above solution, it was assumed that the heat generated by the action of the electric arc is partly used to melt the electrode material and "stored" in liquid drops of material transferred to the welded object. The remaining part of the heat of the electric arc, however, heats the surfacing area directly.

As a result of calculations carried out in [20], heat affected zones were determined (Figure 7). The dimensions and shapes of these zones are consistent with the results of experimental research.

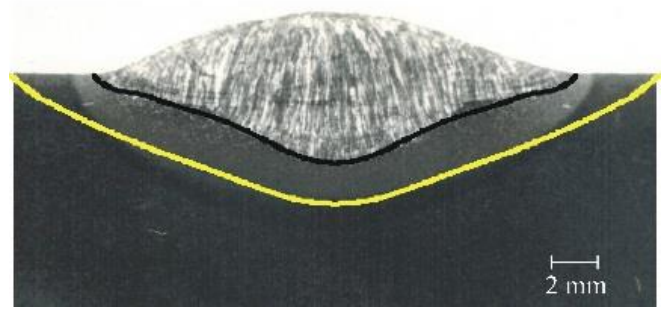

Figure 7 Heat affected zones determined by analytical method [20]

\section{CONCLUSION}

During weld surfacing of flat elements, an irregular shape of the fusion zone is most often obtained. In order to properly calculate the temperature field and, as a consequence, to achieve heat-affected zone, which are consistent with the experimental shapes and dimensions, it is necessary:

- $\quad$ to adopt a two-distributed model of the heat source

- $\quad$ or to apply the thermal load modification proposed in the Sysweld program.

The use of a one-distributed model of the heat source does not give such a possibility. It should be noted that this approach differs from the solutions used for hybrid methods, in which two heat sources are physically accepted. In the case of weld surfacing (or hardfacing), the physical heat source is one, and modeling is based on the appropriate definition of the heat source model or the thermal load of the finite elements (FEM) of the weld padded object.

\section{REFERENCES}

[1] LINDGREN, L. E. Computational Welding Mechanics. Thermomechanical and microstructural simulations. Cambridge: Woodhead Publishing Limited, 2007.

[2] GOLDAK, J. A., AKHLAGHi, M. Computational Welding Mechanics. New York: Springer, 2010.

[3] NGUYEN, N. T.: Thermal Analysis of Welds. Southampton, Boston: WIT Press, 2004.

[4] WINCZEK, J., GUCWA, M., MIČIAN, M., MAKLES, K. Numerical analysis of the influence of electrode inclination on temperature distribution during GMAW overlaying. Mathematical Problems in Engineering, 2019, Article ID 9048025, 13 pages, https://doi.org/10.1155/2019/9048025.

[5] WINCZEK, J., MICIAN, M., IVANOV, V. The modelling of temperature-dependent stress-strain curves for weldable steels, Journal of Applied Mathematics and Computational Mechanics, 2018, vol. 17, no. 3, pp. 111-117.

[6] SAJEK, A., NOWACKI J. Comparative evaluation of various experimental and numerical simulation methods for determination of t8/5 cooling times in HPAW process weldments. Archives of Civil and Mechanical Engineering, 2018, vol.18, no. 2, pp. $583-591$.

[7] GHOSH, A., YADAV, A., KUMAR, A. Modelling and experimental validation of moving tilted volumetric heat source in Gas Metal Arc Welding process. Journal of Materials Processing Technology. 2017, vol. 239, pp. 52-65. 
[8] MIČIAN, M., KONAR, R. Repairs of damaged castings made of graphitic cast iron by means of brazing. Archives of Foundry Engineering. 2017, vol. 17, no. 3, pp. 91-96.

[9] SLADEK, A., PATEK, M., MIČIAN, M. Behavior of steel branch connections during fatigue loading. Archives of Metallurgy and Materials. 2017, vol. 62, no. 3, pp. 1597-1601.

[10] WINCZEK, J., GAWRONSKA, E., GUCWA, M., SCZYGIOL, N. Theoretical and experimental investigation of temperature and phase transformation during SAW overlaying. Applied Sciences. 2019, vol. 9, 1472, pp. 1 -17, https://doi.org/10.3390/app9071472.

[11] WANG, J., HAN, J., DOMBLESKY, J.P, YANG, Z., ZHAO, Y., ZHANG, Q. Development of a new combined heat source model for welding based on a polynomial curve fit of the experimental fusion line. International Journal of Advanced Manufacturing Technology. 2016, vol. 87, pp. 1985-1997.

[12] WINCZEK, J. The influence of the heat source model selection on mapping of heat affected zones during surfacing by welding. Journal of Applied Mathematics and Computational Mechanics 2016, vol. 15, no. 3, pp. 167178.

[13] ROCHALSKI, D., GOLAŃSKI, D., CHMIELEWSKI, T. Models of welding heat sources in the analysis of the temperature field. Welding Technology Review. 2017, vol. 89, no. 5, pp. 109-116.

[14] EAGAR, T. W., TSAI, N. S. Temperature fields produced by travelling distributed heat sources. Welding Journal. 1983, vol. 62, pp. 346s - 355s.

[15] GOLDAK, J., CHAKRAVARTI, A., BIBBY, M. Double ellipsoidal finite element model for welding heat source. II W Doc. No.212-603-85, 1985.

[16] GARCIA-GARCIA, V., CAMACHO-ARRIAGA, J.C., REYES-CALDERON, F. A simplified elliptic paraboloid heat source model for autogenous GTAW. International Journal of Heat and Mass Transfer. 2016, vol. 53, pp. $5774-$ 5781.

[17] HONGYUAN, F., QINGGUO, M, WENLI, X., SHUDE, J New general double ellipsoid heat source model. Science and Technology of Welding and Joining. 2005, vol. 10, pp. $361-368$.

[18] PARKITNY, R., WINCZEK, J. Analytical solution of temporary temperature field in half-infinite body caused by moving tilted volumetric heat source. International Journal of Heat and Mass Transfer. 2013, vol. 60, pp. 469 479.

[19] WINCZEK, J. New approach to modeling of temperature field in surfaced steel elements. International Journal of Heat and Mass Transfer. 2011, vol. 54, pp. 4702-4709.

[20] WINCZEK, J., GAWROŃSKA E. The modeling of heat affected zone (HAZ) in submerged arc welding (SAW) surfacing steel element. Metalurgija. 2016, vol. 55, no. 2, pp. $225-228$.

[21] KIK, T., MORAVEC, J., NOVAKOVA, I. Numerical simulations of X22CrMoV12-1 steel multilayer welding. Archives of Metallurgy and Materials. 2019, vol. 64, no. 4, pp. $1441-1448$.

[22] KIK, T., GÓRKA, J. Numerical simulations of laser and hybrid S700MC T-joint welding. Materials. 2019, 12, 516, doi:10.3390/ma1203051. 